* Discente em Direito pelo Centro Universitário Eurípides de Marília (UNIVEM). Participante do grupo de pesquisa Novos direitos, controle social e aspectos criminológicos (NODICO).

E-mail: dcvalada@hotmail. com

** Graduado em Direito pela Fundação de Ensino Eurípides Soares da Rocha (1988), Mestrado em Direito pela Fundação de Ensino Eurípides Soares da Rocha (2002). Doutorado em Direito pela Universidade Federal do Paraná (UFPR - 2013) e Pós-Doutorado na Universidade de Coimbra (área de Democracia e Direitos Humanos 2016). Atualmente, é professor do Centro Universitário Eurípides de Marília, Graduação e Mestrado, e Delegado de Polícia no Estado de São Paulo.

E-mail: jels@univem.edu.br

\section{A Intervenção do Direito Penal no Crime de Tráfico de Animais e a EducaÇão Ambiental}

\author{
The Intervention Of Criminal Law In The Crime Of \\ Animal Trafficking And The Role Of Environmental \\ EDUCATION
}

\author{
Daniela Cristina Valada* \\ José Eduardo Lourenço dos Santos**
}

Como citar: VALADA, Daniela Cristina; SANTOS, José Eduardo Lourenço dos. A intervenção do direito penal no crime de tráfico de animais e a educação ambiental. Revista do Direito Público, Londrina, v. 14, n. 1, p.103-120, abr. 2019. DOI: 10.5433/1980-511X2019v14n1p103. ISSN: 1980-511X.

Resumo: A Constituição Brasileira veda práticas que coloquem em risco a função ecológica dos animais, provoquem a extinção de espécies ou submetam-nos à crueldade, sendo que o tráfico de animais silvestres fere a Magna Carta em todos estes pontos. Tal atividade gera inúmeros desequilíbrios ao meio ambiente, afetando principalmente a dignidade animal. A lei n. 9.605/98, em busca da tutela ambiental, é ineficaz para atingir os grandes mercadores ambientais, não realizando o objetivo de ser instrumento para a tutela do meio ambiente ecologicamente equilibrado. Além de tudo, trata-se de prática cultural enraizada na população brasileira, principalmente entre as camadas sociais mais pobres. Destarte, a problemática do tráfico persiste na sociedade brasileira, trazendo prejuízos à fauna, ao meio ambiente e à população humana. Objetiva-se no presente estudo analisar a sistemática do crime de tráfico de animais silvestres em conjunto com a legislação infraconstitucional que pretende coibi-lo, sob o norte da Carta Constitucional, a fim de criticar as suas falhas. Ainda, ante o caráter cultural desta prática, pondera-se sobre a importância da educação ambiental como forma de coibir o crime, bem como sobre a importância do desenvolvimento sustentável a fim de trazer o pleno exercício da cidadania.

Palavras-chaves: Educação ambiental. Fauna. Sustentabilidade. Tráfico de animais silvestres. 


\begin{abstract}
The Brazilian Constitution prohibits practices that endanger the ecological wellbeing of animals, such as provoking the extinction of species, trafficking of wild animals and animal cruelty. Such activity generates innumerable and inhumane imbalances in the environment, affecting and forever violating an animal's dignity. Furthermore, law no. 9.605/98, whilst regulating environmental protection, is ineffective in actually protecting it. Additionally, the Brazilian population does not have an eco-friendly culture, especially amongst the poorest, where healthy environmental practices aren't disseminated effectively. Unfortunately, the problem of trafficking still persists in Brazilian society, damaging the environment, its fauna and the surrounding community. All in all, the objective of this study is to analyze the systematics of the crime of trafficking of wild animals in conjunction with Brazilian legislation, which tries to prevent it, under the guidance of Brazilian Constitutional Charter. Moreover, given the cultural nature of this practice, environmental education is an important way to curb this type of crime. Finally, the changing position of the judiciary is important in interpreting environmental norms until Congress can enact laws to better regulate this theme.
\end{abstract}

Keywords: Environmental education; wildlife; sustainability; wildlife trafficking. 


\section{INTRODUÇÃO}

No ano de 2012, o Instituto Brasileiro do Meio Ambiente e dos Recursos Renováveis (IBAMA) publicou um artigo sobre o tráfico de animais silvestres e seus impactos ambientais. Neste estudo, observou-se que cerca de 38 milhões de animais são retirados de seu habitat natural por ano por este comércio ilícito. Ainda, baseado em dados sobre os animais capturados e seus preços, ponderou-se que este comércio movimenta cerca de US\$2,5 bilhões de dólares/ano apenas no Brasil, sendo esta a terceira maior atividade ilícita mundial, atrás apenas do tráfico de drogas e de armas, respectivamente (DESTRO et al., 2012, p. 1). Os números são alarmantes.

Outro estudo que merece destaque é o sistemático e bem elaborado trabalho da organização sem fins lucrativos Rede Nacional Contra o Tráfico de Animais Silvestres (RENCTAS). No Relatório Nacional sobre o Comércio Ilegal da Fauna Silvestre, aponta-se que o comércio de animais e seus subprodutos movimentam cerca de 10 a 20 bilhões de dólares/ano, sendo que o Brasil participa com cerca de 5\% a $15 \%$ do total mundial.

Os números quanto à quantidade de animais retirados conferem com os oferecidos pelo IBAMA, retirando-se o número de animais que morrem antes do destino final (cerca de $90 \%$ deles), é comercializado ilegalmente no Brasil, por ano, 4 milhões de animais silvestres vivos (RENCTAS, 2001).

Registra-se ainda que estes números não são absolutos, já que, como atividade ilegal que é, o tráfico de animais silvestres não conta com registros exatos e muito se perde no processo desde a captura até a comercialização. Além disso, verifica-se que os invertebrados e os peixes, além dos produtos e subprodutos da fauna - que movimentam grande retirada de animais de seu habitat natural pelo tráfico - não constam nesses levantamentos, haja vista a falta de dados e a dificuldade em se realizar as devidas estimativas (RENCTAS, 2001, p. 36).

Observa-se que todos esses animais são retirados da natureza sem ser considerada a capacidade de reposição natural das espécies, o que contribui para a extinção de espécies e para o desequilíbrio ecológico.

Em trecho, o coordenador do relatório do RENCTAS, Dener Giovanini, destaca também a falta de conhecimento e o preconceito contra aqueles incumbidos de defender a fauna. "Em muitos casos, os próprios colegas de farda discriminam quem está lotado nas cooperações que visam à proteção do meio ambiente. Acham um trabalho fácil e "romântico". O preconceito também se mostra presente em diversas delegacias de polícia” (RENCTAS, 2001, p. 4).

Ao tratar da fauna, é de singular importância entender que os animais compõem a grande teia da vida, pois cada qual possui seu indispensável e insubstituível papel no equilíbrio ecológico e nos ecossistemas específicos dos quais fazem parte. Logo, a retirada de um único exemplar da natureza lesa o equilíbrio natural, ferindo assim os demais animais, bem como a população humana, tanto às presentes quanto as futuras gerações humanas.

Vale destacar o disposto no artigo $4^{\circ}$, inciso II, da Lei da Política Nacional de Educação Ambiental, que considera como princípio básico da educação ambiental "a concepção do meio 
ambiente em sua totalidade, considerando a interdependência entre o meio natural, o socioeconômico e o cultural, sob o enfoque da sustentabilidade".

Posto isso, a presente pesquisa busca analisar a atual legislação ambiental de combate ao tráfico de animais, tendo como cerne a proteção constitucional oferecida pela Carta Maior de 1988 e também a intenção do legislador constitucional ao estabelecer a defesa e proteção da fauna brasileira conjuntamente com o princípio da não crueldade com os animais (art. $225, \S 1^{\circ}$, inciso VII) (BRASIL, 1988).

Além disso, há intenção de buscar soluções possíveis para o combate ao ilícito discutido, analisando a fundamental relevância educação ambiental para o combate do crime, além de explorar, durante a discussão do tema, o conceito e aplicação do termo sustentabilidade no que se estende à fauna e ao tráfico de animais, princípio este benquisto na Lei Magna e aplicado como guia por todo o Direito Ambiental Brasileiro.

Por fim, quanto à metodologia, utilizou-se, neste estudo, o método hipotético-dedutivo, além de pesquisa bibliográfica, doutrinária, jurisprudencial e legislativa pertinente ao tema.

\section{A CONSTITUIÇÃO DA REPÚBLICA FEDERATIVA DO BRASIL E A DEFESA DOS NÃO HUMANOS}

A Constituição Federal Brasileira, ao prescrever o direito fundamental de terceira dimensão do meio ambiente ecologicamente equilibrado, em seu artigo $225, \S 1^{\circ}$, VII, dita que incumbe ao Poder Público "proteger a fauna e a flora, vedadas na forma da lei, as práticas que coloquem em risco sua função ecológica, provoquem a extinção de espécies ou submetam os animais a crueldade" (BRASIL, 1988).

A fim de melhor interpretar o Direito, busca-se revelar quais animais são aqueles referidos pela norma constitucional, bem como qual o alcance da palavra crueldade trazida no texto de lei.

Para Silva (2011, p. 201), “[...] a palavra fauna refere-se ao conjunto de todos os animais de uma região ou período geológico" e abrange, portanto, os presentes animais e também os já extintos. No entanto, para Machado (2009, p. 784), a fauna é “[...] o conjunto de espécies animais de um determinado país ou região."

Sem olvidar do saber das definições doutrinárias, deve-se atentar também às delimitações sobre fauna silvestre trazidas pela lei n. 9.605/98, chamada Lei de Crimes Ambientais, em seu artigo $29, \S 3^{\circ}$ :

São espécimes da fauna silvestre todos aqueles pertencentes às espécies nativas, $\mathrm{mi}$

gratórias e quaisquer outras, aquáticas ou terrestres, que tenham todo ou parte de seu ciclo de vida ocorrendo dentro dos limites do território brasileiro, ou águas jurisdicionais brasileiras (BRASIL, 1998).

Enquanto ato cruel é conceito indeterminado, considerado quando atingir a integridade 
físico-psíquica do animal, sendo um mal desnecessário e gratuito, geralmente praticado pela concepção de superioridade da espécie humana sobre os não humanos, sendo caracterizado por diversos tipos de violências como tortura, espancamento, mutilação, abusos, etc (PADILHA; MASSINE, 2009, p. 2452).

Assim, ao vedar tratamento cruel aos animais, o legislador constituinte estaria refutando a visão meramente instrumental da vida animal, a fim de afastar condutas indignas com estes (CASTRO JÚNIOR; VITAL, 2015, p. 18).

Consoante, Padilha e Massine (2009, p. 2461):

A Constituição Federal ao proibir práticas que submetam os animais a crueldade, está direcionando a eles um regramento de consideração de respeito, reconhecendo-os como seres sensíveis e suscetíveis a dor e ao sofrimento, portanto, a questão do sofrimento animal deve ser também considerada pela legislação infraconstitucional e pelos aplicadores do direito, como uma questão moral elevada a nível constitucional, um valor constitucionalmente protegido.

Feitas as ponderações iniciais, infere-se que a hermenêutica possui essencial importância neste tema, haja vista a possibilidade de adoção de posturas antropocêntricas ou biocêntricas ao interpretar a norma constitucional.

Ao analisar a norma constitucional com perspectiva antropológica, tradicional na cultura jurídica nacional, o dever de proteção para com os animais ficaria lesado, já que, segundo esta corrente, todo o dever de proteção aos animais é devido de acordo com a utilidade que estes possuem para o homem, sendo o meio ambiente fonte exclusiva de felicidade e bem-estar do homem, ficando os animais em posição subalterna para com os humanos.

$\mathrm{Na}$ doutrina jurídica nacional, o antropocentrismo encontra entre seus defensores, Fiorillo, que dita que o vocábulo crueldade, previsto na Carta Magna, busca proteger o homem, e não os animais. Isso se daria devido ao fato de que a saúde psíquica humana não permite ao homem ver um animal sofrendo. Ou seja, o fim da norma é unicamente a pessoa humana, sujeita de direitos (FIORILLO, 2015, p. 320-321).

Ainda, Padilha e Massine (2009, p. 2462) nos ensina que:

Sob o prisma antropocêntrico, a natureza e os animais deixam de ser um valor em si, transformando-se em meros recursos ambientais. Tal sistema, ao desconsiderar a singularidade de cada criatura e o caráter sagrado da vida, justifica a tutela da fauna conforme a serventia que os animais possam ter. Tratados, via de regra, como mercadoria, matéria-prima ou produto de consumo, os animais - do ponto de vista jurídico - têm negada a sua natural condição de seres sensíveis.

Por vezes, a visão antropocêntrica está ligada à aplicação do princípio da insignificância, considerando que a retirada de poucas espécies da fauna silvestre caracteriza-se como crime de bagatela, irrelevante ao meio ambiente e ao homem.

Pondera-se que essa interpretação antropocêntrica é prejudicial aos animais e fere a intenção 
do legislador constituinte ao escrever sobre a fauna. Dessa forma, defende-se aqui uma postura biocêntrica ao se interpretar o texto da Lex Mater no que concerne ao meio ambiente.

A visão biocêntrica é aquela que considera o ser humano como parte integrante do meio ambiente, não como parte dominante deste. Sendo assim, a fauna - e todo o meio ambiente - deve ser tutelada devido seu valor próprio, independentemente de sua serventia para o homem.

Em grande salto qualitativo do judiciário, há julgados que afastam o princípio da insignificância ao tratar da fauna brasileira e adotam, assim, a perspectiva biocêntrica ao tratar desse tema, como por exemplo:

AGRAVO REGIMENTAL NO AGRAVO EM RECURSO ESPECIAL. VIOLAÇÃO DO PRINCÍPIO DA COLEGIALIDADE. NÃO OCORRÊNCIA. CRIMEAMBIENTAL.ART.34,PARÁGRAFOÚNICO,II,DALEIN. 9.605/1998. PRINCÍPIO DA INSIGNIFICÂNCIA. INAPLICABILIDADE. ATIPICIDADE DE CONDUTA. NÃO OCORRÊNCIA. AGRAVO REGIMENTAL NÃO PROVIDO. 2. Na espécie, embora não haja sido apreendido nenhum pescado, é significativo o desvalor da conduta do agravante, haja vista não apenas o local da atividade pesqueira - área de reserva biológica -, mas também a forma como foi praticado o delito (utilização de redes) se mostrarem potencialmente capazes de colocar em risco a reprodução das espécies da fauna local. 3. Ademais, a captura é mero exaurimento da figura típica em questão, que se consuma com a simples utilização do petrecho não permitido. $\mathrm{O}$ dano causado pela pesca predatória não se resume, portanto, às espécimes apreendidas. 4. Agravo regimental não provido (Superior Tribunal de Justiça. AgRg no AREsp 1172493/SC, da $6^{\mathrm{a}}$ Turma, relator: Ministro Rogerio Schietti Cruz. Brasília, 21/06/2018) (BRASIL, 2018).

Ademais, os crimes contra o meio-ambiente são considerados crimes de acumulação, pois não se pode compreender o dano ou perigo de dano em uma conduta isolada - como retirar apenas um exemplar da fauna de seu habitat - todavia, a lesão passa a ser compreendida quando se leva em consideração a acumulação de condutas semelhantes e reiteradas.

Os crimes de acumulação têm por objetivo proteger interesses supraindividuais - como o meio ambiente - sustentando a punição da conduta isolada, mesmo sem a lesividade aparente, e sim projetada, afastando a aplicabilidade do princípio da insignificância (CUNHA, 2015, p. 169).

Porfim, observa-se que a prática cultural brasileira com os animaisé ainda predominantemente antropocêntrica, já que uma parcela significativa da fauna é submetida dia após dia a atos de maus tratos e extermínio, considerados naturais e legítimos pela maioria da população.

Inclusive, adotar posturas antropocêntricas validam as práticas de maus tratos e mortes diárias sofridas pelos animais para fins alimentares, de vestuário, entre outros, o que não contribui com a evolução dos institutos no que é possível - como o caso do tráfico de animais.

À vista disso, a inovação trazida pela Constituição Federal torna-se quimera, cabendo ao judiciário, como órgão vivo do direito, analisar e progredir em seus julgados de forma benéfica aos não humanos na medida de sua capacidade, auxiliando na implementação das normas ambientais ao adotar uma visão biocêntrica, promovendo assim a conscientização e a educação ambiental e 
contribuindo com a evolução da cultura brasileira em prol do meio ambiente, dos animais e da vida.

Por fim, a fim de proteger o meio ambiente, estabelece o texto constitucional o mandado de criminalização previsto no artigo $225, \S 3^{\circ}$, “As condutas e atividades consideradas lesivas ao meio ambiente sujeitarão os infratores, pessoas físicas ou jurídicas, a sanções penais e administrativas, independentemente da obrigação de reparar os danos causados" (BRASIL, 1988).

Assim, respeitando o imperativo constitucional, fica estabelecido um sistema tríplice de responsabilidade na seara ambiental, no sentido de que o causador de dano ambiental pode ser submetido à responsabilização na esfera cível, administrativa e penal.

\section{DA LEI DE CRIMES AMBIENTAIS}

Na esfera penal, há a Lei nº 9.605/98 - denominada Lei de Crimes Ambientais - que diz, em seção especial de tutela da fauna, o que é o tráfico de animais, configurando-se em "matar, perseguir, caçar, apanhar, utilizar espécimes da fauna silvestre, nativos ou em rota migratória, sem a devida permissão, licença ou autorização de atividade competente, ou em desacordo com a obtida" (art. 29), além de elencar nos incisos I, II e III do $§ 1^{\circ}$ variáveis do mesmo crime e cumular como sanção penal a detenção e a multa (BRASIL, 1998).

Ademais, o artigo 32 da referida lei proíbe atos de abuso, maus-tratos, ferir e mutilar animais, sendo estes silvestres, domésticos ou domesticados, nativos ou exóticos, ocorrendo aumento de pena com a morte do animal (Art. 32, §2º (BRASIL, 1998).

Este último artigo representa um avanço na defesa dos animais, onde maus-tratos passaram de contravenção penal a crime, ainda que de menor potencial ofensivo, de acordo com a Lei $n^{\circ}$ 9.099/95. Porém, observa-se aqui que, consoante esta lei, o réu primário não chega a ser julgado, tendo o benefício da transação penal com o Ministério Público (BRASIL, 1995).

Neste ponto, destaco crítica doutrinária no sentido de que o Direito Penal é ineficaz para solução de conflitos na seara ambiental. Neste sentido, os crimes ambientais estariam atrelados à função promocional do Direito Penal, que seria influenciado pelo poder político em casos que seriam melhor solucionados pela via administrativa (VIVIANI, 2016, p. 725).

Ainda, o Direito Penal estaria a fomentar a desigualdade através da reprodução de conflitos e lesões a bens jurídicos individuais, enfraquecendo o Estado Democrático de Direito e agravando os problemas sociais haja vista a sua seletividade e violência, não cumprindo sua função de proteger o meio ambiente (BALDISSERA; AQUINO, 2016).

Combatendo estas críticas, realço que, conforme preceitua a parte geral do Código Penal, a aplicação de pena deve ser necessária e suficiente para a reprovação e prevenção do crime, conforme prevê o artigo 59 do Código Penal (BRASIL, 1940).

Assim, tem-se que o Direito Penal possui as funções retributiva e preventiva. No aspecto preventivo, tem-se que o estabelecimento de crimes, respeitando-se a legalidade que consubstancia o garantismo, gera a utilidade geral de prevenção, atuando negativamente como coação psicológica, 
buscando a intimidação dos cidadãos a não cometerem crime, sob a ameaça da aplicação da pena.

Já o aspecto preventivo especial da pena, negativamente atua com a imposição da sanção penal, e positivamente com a reeducação e ressocialização do condenado. Neste último, considerase que todo o constrangimento de passar por um processo penal como réu serve também para a reeducação do criminoso, o que contribui para a inibição de novo crime, principalmente nestes nos que não se auferem lucros como a crueldade e maus-tratos (QUEIROZ, 2008).

Destarte, considerando o mandado constitucional de criminalização expresso na Constituição Federal, tem-se que o meio ambiente é um bem que deve ser juridicamente protegido, em função protetiva estendida para a esfera penal, buscando cumprir seu dever de proteger bens jurídicos.

Inclusive, as necessidades contemporâneas há muito passaram a exigir uma mudança de paradigma do Direito Penal, a fim de expandir seu âmbito de atuação para bens jurídicos coletivos, sendo estes valores de suma importância para a vida humana coletiva.

Deste modo, surge a Lei de Crimes Ambientais, que tem por objetivo sancionar penalmente todas as infrações ambientais, e, quando possível, efetuar o reparo ambiental. Antes mesmo, considerando a função preventiva geral da pena acima delineado, tem-se que esta lei auxilia na concretização do princípio ambiental de prevenção (TAKADA; RUSCHEL, 2012), intimidando os cidadãos a não degradarem o meio ambiente sob ameaça da sanção penal.

Porém, quando versa sobre o tráfico de animais silvestres, esta recebe muitas críticas pela ausência de técnica legislativa que culmina em sua ineficácia, além de críticas quanto a ampla utilização de conceitos indeterminados, amplos, imprecisos, vagos e ambíguos, fazendo-se questionar se não há ofensa ao princípio penal da taxatividade (ELIEZER, 2016).

Neste ponto específico, aponta-se que os tipos penais previstos na lei criminal ambiental, eivados de impropriedades técnicas, linguísticas e lógicas, permeados de cláusulas valorativas e, frequentemente, vazados em normas penais em branco, passam a depender excessivamente da acessoriedade administrativa, que é a dependência do Direito Penal em relação do Direito Administrativo (ELIEZER, 2016).

Críticos apontam que a legislação, por ser evasiva, não consegue atingir o verdadeiro traficante da fauna, já que não diferencia o pequeno mercador daqueles que auferem grandes lucros com a ilicitude. Sendo assim, geralmente são processados os empregados dos traficantes - os motoristas do caminhão, funcionário da venda, etc. - e não os comandantes do tráfico (PADILHA; MASSINE, 2009, p. 2458).

Quanto à dosimetria da pena no ilícito do tráfico, deve-se memorar que o antigo Código de Caça previa reclusão de 2 a 5 anos para o comércio ilegal. Na atual legislação, a pena não passa de detenção de no máximo um ano, e multa (PADILHA; MASSINE, 2009, p. 2459). Se for primário, o réu não é processado. Caso contrário, trata-se de pena a ser cumprida integralmente em regime aberto e geralmente convertida em penas restritivas de direitos. Para um comércio que obtém lucros tão exuberantes como este, a referida sanção penal é irrisória.

Quanto à impropriedade linguística, tem-se a lastimável redação dos artigos, por exemplo, o artigo 29, que utiliza a expressão espécimes, no plural, remetendo a ideia de que o crime cometido 
com apenas um exemplar da fauna seria atípico.

Já o artigo 30 também possui problemas em sua formulação. Consistindo em "exportar para o exterior peles e couros de anfíbios e répteis em bruto, sem a autorização da autoridade competente" - trata-se de, além de pleonástico, da letra fria da lei entender-se que o comércio interno de peles e couros sem a devida autorização seria, novamente, fato atípico (PADILHA; MASSINE, 2009, p. 2459-2460).

\section{DO TRÁFICO DE ANIMAIS SILVESTRES}

Superada a questão acerca da legislação penal pertinente a matéria, importante ressaltar a sistemática do crime de tráfico de animais silvestres, justificando a importância da presente temática.

Inicialmente, aponta-se que este comércio ilegal se utiliza de diversos tipos fraudulentos para obter sucesso. Conforme o relatório elaborado pela organização sem fins lucrativos RENCTAS, os traficantes se utilizam do contrabando por meio das fronteiras, pois atuam em áreas de difícil patrulhamento como os limites do Brasil na Amazônia; uso de documentos falsos nos quais as espécies, número, origem, entre outros fatores não coincidem com os fatos; suborno de autoridades; entre outras atividades fraudulentas que se encontram em constantes mudanças, conforme a necessidade dos traficantes.

Ainda, elenca três principais meios de fraudes envolvidos no tráfico, sendo: contrabando, uso de documentos legais para cobrir coisas ilegais e uso de documentos falsos, ainda dita que há diversos outros tipos de fraudes impossíveis de serem todas listadas devido à variedade delas. Sempre que um tipo de fraude é detectado, outro já está emergindo (RENCTAS, 2001, p. 25-27).

Assim, observa-se o caráter transfronteiriço do tráfico, fazendo-se necessária uma legislação e cooperação internacional ao combate do tráfico, bem como, sob outro prisma, analisa-se que referido comércio consiste em uma afronta ao estado de direito democrático, já que, dentre os diversos problemas por ele gerado, inclui-se o fortalecimento das redes criminosas, ameaça à saúde populacional, desequilíbrio ecológico e sofrimento animal.

Os traficantes são diversos, consistindo em: pequenos traficantes, aqueles compostos por populações carentes que retiram do meio ambiente os animais como forma de complementar a renda, também considerados fornecedores; médios traficantes aqueles que podem, assim como os pequenos, ser facilmente substituídos por outros mais eficientes, e que fazem a conexão com os grandes traficantes que atuam nacional ou internacionalmente e retiram grandes lucros desse mercado, familiarizados com os vários tipos de corrupção, por vezes infiltrados em órgãos públicos, formando grandes redes criminosas com grande facilidade em mobilidade, o que dificulta ainda mais seus mapeamentos (RENCTAS, 2001, p. 28-29).

Entre os motivos destacados para o crescimento do tráfico inclui-se o descaso com que este é considerado, já que parte das polícias, alfândegas e autoridades judiciais não o consideram como um crime sério, de suma importância. Sendo assim, o recurso destinado a combater esse comércio 
é muito pequeno para a real necessidade, o que contribui para maior interesse dos traficantes por esse comércio, uma vez que o lucro é quase igual ao do tráfico de drogas e os riscos de sobremaneira menores.

Além disso, a grande demanda de fiscalização decorrente do crescimento geral do comércio internacional nos últimos anos implica menor possibilidade de averiguar toda a mercadoria, auxiliando não apenas este comércio ilícito, como também todos os demais (RENCTAS, 2001, p. 16).

O relatório do RENCTAS, supracitado, também aponta que por vezes o comércio ilegal de animais silvestres tem ligações com outras quadrilhas como as de contrabando de drogas, armas e pedras preciosas e que, muitas vezes, os traficantes utilizam dos animais transportados para armazenar drogas, sendo relatadas situações em que se encontram sacos de cocaína dentro do estomago dos animais, em suas peles ou junto com os containers que os transportam. Ainda:

Pesquisa e acompanhamento das atividades dos traficantes, realizados pelo RENCTAS, sugerem que no Brasil existe cerca de 350 a 400 quadrilhas organizadas que realizam o comércio ilegal de fauna silvestre, e dessas, cerca de 40\% possuem ligações com outras atividades ilegais (RENCTAS, 2001, p. 53).

Quanto à saúde populacional, conforme disposto no estudo da rede RENCTAS, tende-se que uma grande quantidade de zoonoses é trazida pelas péssimas ou inexistentes práticas sanitárias dos animais transportados, geralmente, em rota do norte ao sul do país ou então na tríplice fronteira Brasil, Paraguai e Argentina.

Entre as zoonoses comumente transmitidas estão: febre amarela, hepatite A, tuberculose, salmonelose, raiva, toxoplasmose, psitacose (febre do papagaio), entre diversas outras. Muitas dessas doenças, se não tratadas adequadamente, podem levar à morte do paciente.

Pesquisas apontam que já são conhecidas mais de 180 doenças transmitidas de animais para humanos e, com as precárias condições em que são transportados, juntamente com o estresse enfrentado por esses animais, ocorre a queda da resistência imunológica destes, transformando-os em hospedeiros ideais para diversos agentes infecciosos (RENCTAS, 2001, p. 54-55).

A lembrar, a Constituição Federal de 1988 elenca como direito social fundamental a saúde, previsto em seu artigo $6^{\circ}$. Ainda, no artigo 196, dita que “[...] a saúde é direito de todos e dever do Estado, garantido mediante políticas sociais e econômicas que visem a redução do risco de doença e de outros agravos [...]" (BRASIL, 1988).

Além do mais, todo o dinheiro movimentado pelo tráfico não tem retirados os impostos. Porém, tendo em vista a proteção constitucional dos animais, mesmo que este comércio fosse regularizado tributariamente, ainda sim haveria grande crítica ao desprezo pelo qual os animais traficados são relegados.

Nesta hipótese, haveria a regularização do comércio de animais silvestres com a produção desses animais em cativeiro, com fins comerciais, criando uma indústria poderosa que geraria benefícios, como a grande movimentação econômica e a geração de empregos - fundamentais em 
tempos de crise -, além de manter viva a antiga prática cultural de criar de animais silvestres em cativeiro.

Seria a descriminalização do tráfico de animais silvestres. Porém, tal comércio consistiria em crueldade consentida, uma vez que o animal deve ser livre. Além disso, esses animais criados para o comércio dificilmente alcançariam os baixos preços oferecidos pelo tráfico.

A descriminalização do tráfico de animais silvestres não é a solução. Este comércio afeta, principalmente, aquele que não escolheu participar da rede criminosa e que sofre todas as consequências, qual seja: o animal.

Destaca-se ainda que o tráfico de animais silvestres está diretamente relacionado com o contexto socioeconômico do país. Quanto mais pobre o país, pior é sua educação e maior o seu desemprego, levando a população a participar deste comércio, considerado normal pela a maioria destes indivíduos, prejudicando de sobremaneira a implementação judicial contra o ilícito.

Devem ser criados mecanismos mais eficientes para o controle e prevenção do tráfico de animais silvestres, momento em que destaco a falta de dados organizados e sistematizados sobre o tráfico de animais, além de estudos escassos sobre os impactos ambientais.

Há, neste item, especial importância ao associar o conhecimento técnico sobre o tema com o melhor desempenho da inteligência policial. Necessita-se do auxílio e grande investimento na Polícia Ambiental e Florestal, como principal agente de perquirição aos criminosos, além de investimentos ao setor de inteligência policial para o combate a grandes redes criminosas, como o caso do tráfico de animais.

No mais, há de se ter em mente que o destino dos animais também é diverso, consoante o Relatório do RENCTAS supracitado, há cinco destinos para a fauna e seus subprodutos, sendo: 1- Animais para colecionadores particulares e zoológicos, onde se prioriza espécimes raros. Quanto mais raro for o animal, maior seu valor no mercado negro - a arara-azul-de-lear, por exemplo, alcança preço médio de $\mathrm{R} \$ 60.000,00$ (sessenta mil reais) por unidade; 2- Animais para fins científicos (biopirataria), que consiste na exploração e comercialização ilegal do patrimônio genético de determinada localidade e das substâncias químicas fornecidas por determinados animais; 3- Animais para serem vendidos em feiras livres, pet shops e via internet, sendo a modalidade mais popular no Brasil; 4- Produtos da fauna, equivalendo a peles, couros, garras, penas, além de vários tipos de souvenires (RENCTAS, 2001, p. 17-20).

Quanto à biopirataria animal, faz-se necessário ressaltar que toda prática desta resulta do tráfico de animais silvestres, mas nem todo tráfico de animais silvestres resulta em biopirataria, apesar de ser este um dos ramos mais lucrativos do tráfico.

A Lei de Crimes Ambientais (Lei n 9.605/98) não possui tipificação própria à biopirataria, dependendo de uma visão extensiva do jurista para a aplicação da pena, ante a ausência legislativa (BRASIL, 1998). Ocorre esta prática, por exemplo, com a manipulação ilegal do veneno de cobras para a produção de soros antiofídicos.

Há, ainda, a necessidade conscientização da população, políticos e principais líderes da sociedade brasileira para a proteção do meio ambiente e do patrimônio genético. É fundamental 
apoio governamental para as políticas e defesas ao meio ambiente, e consequentemente a fauna. Fauna esta, que mais sofre com o descaso humano.

Isto porque, a forma como este comércio se desdobra atesta típicas formas de crueldade e desumanidade com os animais. Por exemplo, aves frequentemente são sedadas e transportadas dentro de cubos de PVC (policloreto de polivinila) ou dentro de caixas superlotadas, sem água ou alimento, onde brigam, se mutilam e se matam (PADILHA; MASSINE, 2009, p. 2453).

Ainda, para acalmar os animais, por vezes os traficantes as oferecem bebidas alcoólicas. Para fazê-las parecerem mais mansas aos compradores e chamar menos atenção dos fiscalizadores, por vezes cegam-se os olhos, arrancam dentes e garras, quebram-se ossos, entre outras diversas práticas cruéis realizadas (PADILHA; MASSINE, 2009, p. 2453).

Consoante com Padilha e Massine (2009, p. 2450):

Ao serem retirados de seu hábitat natural, os animais traficados são vítimas de inúmeras crueldades e maus tratos, o que leva a maioria deles à morte, em consequência, por exemplo, da amputação de seus membros, dentes e garras, do transporte em condições precárias e sem nenhuma consideração por seu bem-estar. $\mathrm{Na}$ prática do tráfico de animais silvestres não há qualquer limite humanitário por parte dos traficantes, que são capazes de qualquer coisa com suas vítimas indefesas, no intuito de burlarem a fiscalização das autoridades competentes e alcançarem o seu intento.

Estas crueldades são refletidas na quantidade de animais que morrem com este comércio: aproximadamente $90 \%$ dos animais retirados de seu habitat natural pelo tráfico de animais morrem antes de chegarem ao destino final, ou seja, cerca de 34 milhões de animais por ano.

Destarte, o tráfico de animais silvestres auxilia a colocação de diversas espécies em extinção, colaborando com o desequilíbrio ecológico. Apesar da megabiodiversidade brasileira, deve-se notar que várias populações contam com poucos exemplares, tornando-as ainda mais frágeis e suscetíveis ao desaparecimento com a atividade do tráfico.

\section{A IMPORTÂNCIA DA EDUCAÇÃO AMBIENTAL E DO DESENVOLVIMENTO SUSTENTÁVEL}

Charles Darwin, precursor da biologia moderna, em seu brilhante legado nos mostrou que os seres vivos vertebrados da terra são iguais a nós em suas principais funções, diferindo apenas em grau e complexidade. Portanto, os mecanismos de prazer e dor são expressos da mesma forma por humanos e animais, de acordo com a idade e estado de espírito. Preconizou estudos sobre a senciência animal (capacidade de sentir dos animais) (DARWIN, 2014).

Peter Singer, um dos autores e ativista de maior renome no Direito dos Animais, defende que a tutela, não só do Estado, mas principalmente da sociedade, é devida a todo ser capaz de sentir dor. Em seu livro Libertação Animal, defende que devemos evitar a dor do próximo independentemente de ser animal ou ser humano, e que esta é a máxima a ser seguida para uma 
sociedade mais digna, justa e coerente (SINGER, 2013).

Pela senciência animal - comprovada pela ciência -, e por empatia ao próximo com respeito à alteridade, há com os animais inferiores o dever de tutela ética. $\mathrm{O}$ exercício do respeito aos animais é um exercício de amor ao próximo, de caridade e principalmente de educação. Traz empatia e maior respeito não apenas com os animais inferiores, mas também com os iguais em espécie, melhorando inclusive o convívio entre humanos.

Daí a importância da conscientização ambiental, expandindo horizontes da população por meio do ensino, trazendo a todos um novo olhar sobre o mundo, um olhar em que as questões ambientais possuem central importância, para que todos saibam que a destruição do habitat acarreta malefícios a todos e o desrespeito ao próximo seja inaceitável por qualquer pessoa.

Vê-se, nitidamente, a importância da educação ambiental, previsto no artigo 225, inciso VI, da Constituição Federal, com o intuito de conscientizar a todos sobre o respeito ao meio ambiente, sendo assim, também à fauna, de forma que, em longo prazo, esse mercado ilegal tenha sua clientela drasticamente reduzida, dizimando uma das principais balizas sustentadoras desse comércio.

Assim, nos dizeres de Viviani (2016, p. 730-731):

É certo que o Direito Penal não tem o condão de solucionar todas as mazelas e conflitos oriundos de agressões que afetem o meio ambiente, até porque se trata de um bem jurídico difuso com definição demasiadamente ampla. Além disso, como forma de assegurar o valor da sustentabilidade em sua plenitude, é imperativo que o Estado (especialmente os Poderes Executivo e Legislativo) implemente políticas públicas efetivas tendentes a preservar o meio ambiente, inclusive investindo na educação ambiental.

Atuando em auxílio ao Direito Penal na tarefa de reduzir as degradações ambientais, a educação ambiental, regulada pela Lei $n^{\circ} .9 .795 / 99$, é definida, em seu artigo $1^{\circ}$, como sendo:

Art. $1^{\circ}$ : Entendem-se por educação ambiental os processos por meio dos quais o indivíduo e a coletividade constroem valores sociais, conhecimentos, habilidades, atitudes e competências voltadas para a conservação do meio ambiente, bem de uso comum do povo, essencial à sadia qualidade de vida e sua sustentabilidade (BRASIL, 1999).

Ou seja, para a mudança do cenário de degradação e desrespeito ambientais, faz-se necessária uma mudança de postura por parte da população, mudança essa conseguida através da educação ambiental pautada na ética, o que gera consciência ecológica.

Nesse sentido, Sirvinskas (2009, p. 12 apud MASSINE, 2010, p. 5) afirma:

Surge a questão da ética ambiental para nortear o ser humano no agir ambiental, ou seja, para a sua relação com o meio ambiente. Assim, a educação ambiental para ser eficaz precisa estar calcada em uma ética ecológica, entendida esta como 
'a compreensão que o homem tem da necessidade de preservar ou conservar os recursos essenciais à perpetuação de todas as espécies de vida existentes no planeta'.

A consciência ecológica está umbilicalmente ligada à mudança de comportamento humano em prol do meio ambiente. Como explanado, quanto menor o nível social de uma população maior o desrespeito e envolvimento com o tráfico de animais silvestres. Isto porque o desrespeito, o desconhecimento e a ignorância nas questões ambientais contribuem para a conivência com essas degradações ambientais. Assim, a consciência ecológica faz com que a pessoa repudie tais atos de desrespeito aos animais e ao meio ambiente, mudando assim de postura perante tais fatos.

Atenta-se aqui também ao conceito de desenvolvimento sustentável, inclusive previsto no artigo $1^{\circ}$ da Lei de Educação Ambiental, já citado. De acordo com Thomé (2015, p. 58-59), haverá desenvolvimento sustentável sempre que o Estado harmonize três vertentes simultaneamente, sendo estas: crescimento econômico, preservação ambiental e equidade social. Ainda, é necessário que este desenvolvimento satisfaça as necessidades da atual geração sem comprometer a capacidade de autogerir das futuras gerações.

Observa-se que a Constituição do Brasil prevê, no artigo 170, inciso VI, como princípio da ordem econômica, a defesa do meio ambiente, demonstrando a clara necessidade de harmonização entre a atividade econômica e a preservação ambiental (BRASIL, 1988).

A Magna Carta institui, ainda, no supracitado artigo 225, e dever de defesa e preservação do meio ambiente - imposição de ações positivas do poder público - não apenas para as presentes gerações, mas também para as futuras, configurando assim o princípio da equidade intergeracional ou solidariedade intergeracional, pilar do desenvolvimento econômico sustentável.

Citando Padilha (2014, p. 8-9):

As normas de proteção do meio ambiente atuam como um complemento aos direitos do homem, principalmente o direito à vida digna e à saúde, direitos que não se efetivam sem a qualidade ambiental, o homem e o meio ambiente fazem parte da mesma teia da vida, portanto, a efetividade das normas ambientais implica na efetividade dos direitos humanos fundamentais.

Vê-se que a eficácia da proposta constitucional de defesa do meio ambiente passa por inúmeras dificuldades no plano fático, tendo em vista que geralmente se choca com interesses econômicos antagônicos à preservação do meio ambiente, deixando claro, novamente, a importância do judiciário como implementador da norma constitucional ambiental.

Ainda, há clara relevância da necessidade de consciência ambiental a todo órgão jurisdicional, que deve observar na solução de lides o princípio primordial jusnaturalista de preservação da vida.

Por fim, interessante a vinculação existente entre a educação ambiental, a sustentabilidade do meio e a cidadania. Dessa forma, a educação ambiental, gerando consciência ecológica, gera também consciência política, visto que cidadão politicamente ativo é aquele que possui saber crítico, obtido através da educação e do conhecimento, para então exigir mudanças ativas dos 
poderes públicos e coadunar com posições políticas com base em premissas pré-questionadas.

De acordo com Massine (2010, p. 7):

Não é possível afastar meio ambiente, sustentabilidade, política e cidadania. A questão da cidadania está profundamente ligada à noção de direitos e deveres, sobretudo os políticos. Nesse sentido, a educação ambiental age na produção de conhecimento político, campo onde se realiza a cidadania, para que haja a implementação de uma sustentabilidade eficaz, vez que propicia ao cidadão uma participação ativa na gestão e na organização do meio em que vive.

Assim, a educação ambiental auxilia no saber crítico da população, que passa então a exigir posturas ativas dos órgãos públicos a fim de defender os animais e dizimar o tráfico destes. Ainda, faz a mudança de postura populacional, que deixa de ser conivente situações degradantes e passa a participar da luta contra a exploração animal.

\section{CONSIDERAÇÕES FINAIS}

A retirada de animais silvestres de seu habitat natural para o comércio ilegal consiste em desequilíbrio ambiental, vez que é um grande impacto ambiental que representa uma afronta ao Estado de Direito, ofensa à dignidade animal, além de, no caso específico da biopirataria, agravo ao patrimônio genético brasileiro.

De acordo com o estudo aqui desenvolvido, percebe-se a necessidade da consciência ecológica dos órgãos jurisdicionais para superação do paradigma antropológico que circunda o pensamento jurídico nacional. O desenvolvimento de uma linha de pensamento biocêntrica mostra-se favorável à fauna, e, em última instância, à população humana também, haja vista a complexidade da teia da vida onde todo animal possui seu papel insubstituível e toda vida afeta milhares de outras vidas.

Observa-se que a legislação criminal-ambiental nacional é evasiva e pleonástica, sem a diferenciar o pequeno traficante ao grande mercador de animais, e, ainda, a dosimetria das penas se mostram ineficazes e inadequadas quando defronte à grande movimentação financeira que esta ilicitude gera.

Foram observadas também as características do tráfico de animais silvestres no país, como, por exemplo, as pessoas que neste comércio são envolvidas e a associação deste com outras redes criminosas, como a rede de drogas.

Também, associa-se esse comércio ao desenvolvimento social: quanto mais subdesenvolvido o país encontra-se, maior o envolvimento e aceitação de sua população com tráfico de animais. Nesse sentido, o desenvolvimento social, juntamente com a preservação do meio ambiente e o desenvolvimento econômico formam as premissas basilares do desenvolvimento sustentável, previsto na Constituição Federal (art. 170 e 225).

Analisou-se o papel fundamental da educação ambiental no combate ao tráfico de animais 
silvestres, uma vez que a educação ambiental gera consciência ecológica, e esta última gera mudança de postura da população, que deixa de ser conivente com a situação e passa a exigir posturas ativas de combate ao tráfico de animais silvestres por parte dos poderes públicos, assim, gerando também consciência política e o exercício da cidadania.

O tráfico de animais silvestres, como toda rede criminosa, deve ser coibido de forma eficaz, propiciando, por um lado, a inibição dessa ação criminosa, por outro, a liberdade e dignidade animal, e, consequentemente, melhora do meio, da saúde e da qualidade de vida populacional, uma vez que o meio ambiente ecologicamente equilibrado é essencial a sadia qualidade de vida.

Por fim, anota-se que o tráfico de animais silvestres, comércio ilegal que em nada respeita ao meio ambiente, deve ser estudado, criticado, tratado nas academias e escolas brasileiras, tratado pelos governantes, pelos juristas, pela mídia, e, principalmente, combatido em todas as esferas da sociedade, desde a população, os governantes, órgãos jurisdicionais, mídia e as forças militares, haja vista as irreversíveis consequências que esta prática ilícita traz ao meio ambiente, à população humana e aos animais.

\section{REFERÊNCIAS}

BALDISSERA, Rafaela; AQUINO, Sérgio Ricardo Fernandes. A ilusória tutela penal de um meio ambiente sustentável. Revista Eletrônica Direito e Política, Itajaí, v. 11, n. 2, 2016.

BRASIL. [Constituição (1988)]. Constituição da República Federativa do Brasil DE 1988.

Brasília: Presidência da República, 1988. Disponível em: http://www.planalto.gov.br/ccivil_03/ Constituicao/Constituicao.htm. Acesso em: 1 dez. 2018.

BRASIL. Lei n. 2848, de 7 de dezembro de 1940. Código Penal. Brasília: Presidênia da República, 1940. Disponível em: http://www.planalto.gov.br/ccivil_03/decreto-lei/ Del2848compilado.htm. Acesso em: 29 nov. 2018.

BRASIL. Lei n. 9099, de 26 de setembro de 1995. Dispõe sobre os Juizados Especiais Cíveis e Criminais e dá outras providências. Brasília: Presidência da República, 1995. Disponível em: http://www.planalto.gov.br/ccivil_03/LEIS/L9099.htm. Acesso em: 2 dez. 2018.

BRASIL. Lei n. 9605, de 12 de fevereiro de 1998. Dispõe sobre as sanções penais e administrativas derivadas de condutas e atividades lesivas ao meio ambiente, e dá outras providências. Brasília: Presidência da República, 1998. Disponível em: http://www.planalto.gov. br/ccivil_03/LEIS/L9605.htm. Acesso em: 1 dez. 2018.

BRASIL. Lei n. 9795, de 27 de abril de 1999. Dispõe sobre a educação ambiental, institui a Política Nacional de Educação Ambiental e dá outras providências. Brasília: Presidência da República, 1999. Disponível em: http://www.planalto.gov.br/ccivil_03/LEIS/L9795.htm. Acesso em: 2 dez. 2018.

BRASIL. Superior Tribunal de Justiça. Agravo Regimental no Agravo em

Recurso Especial n. 1172493/SC. 6 a Turma. Relator: Ministro Rogerio Schietti Cruz. Brasília, 21 de junho de 2018. Disponível em: https://ww2.stj.jus.br/processo/ revista/documento/mediado/?componente=ATC\&sequencial $=84881629 \&$ num $_{-}$ 
registro $=201702461034 \&$ data $=20180801 \&$ tipo $=5 \&$ formato $=$ PDF. Acesso em: 20 fev. 2019.

CASTRO JUNIOR, Marco Aurélio; VITAL, Aline de Oliveira. Direito dos animais e a garantia constitucional de vedação à crueldade. Revista Brasileira de Direito Animal UFBA, Salvador, v. 10, n. $18,2015$.

CUNHA, Rogério Sanches. Manual de direito penal: parte geral. 3. ed. Bahia: Editora Juspodivm, 2015.

DARWIN, Charles. A origem das espécies. São Paulo: Editora Martin Claret, 2014.

DESTRO, Guilherme Fernando Gomes; PIMENTEL, Tatiana Lucena; SABAINI, Raquel Monti; BORGES, Roberto Cabral; BARRETO, Raquel. Esforços para o combate ao tráfico de animais silvestres no Brasil. Intechopen, [S. l.], 29 ago. 2012. Disponível em: http://www.ibama.gov.br/ sophia/cnia/periodico/esforcosparaocombateaotraficodeanimais.pdf. Acesso em: 28 nov. 2018.

ELIEZER, Cristina Rezende; REIS, Mattheus Phillipe. Uma breve análise crítica sobre a Lei dos Crimes Ambientais face ao princípio da taxatividade. Revista do Curso de Direito da UNIFOR, Formiga, v. 7, n. 1, 2016.

FIORILlO, Celso Antonio Pacheco. Curso de direito ambiental brasileiro. 15. ed. São Paulo: Editora Saraiva, 2015.

MACHADO, Paulo Affonso Leme. Direito ambiental brasileiro. 17. ed. São Paulo: Editora Malheiros, 2009.

MASSINE, Maiara Cristina Lima. Sustentabilidade e educação ambiental: considerações acerca da política nacional de educação ambiental - a conscientização ecológica em foco. In: ENCONTRO NACIONAL DO CONPEDI, 19., 2010, Fortaleza. Anais [...]. Fortaleza: CONPEDI, 2010. p. 2757-2770. Disponível em: http://www.publicadireito.com.br/conpedi/ manaus/arquivos/anais/fortaleza/3544.pdf. Acesso em: 29 nov. 2018.

PADILHA, Norma Sueli. O compromisso constitucional brasileiro com a sustentabilidade ambiental. [2014?]. Disponível em: http://www.publicadireito.com.br/artigos/?

cod=152c97a9bb6f2aba. Acesso em: 27 nov. 2018

PADILHA, Norma Sueli; MASSINE, Maiara Cristina Lima. O paradigma constitucional de práticas que submetam os animais a crueldade: uma análise da razão antropocêntrica da cultura jurídica brasileira na implementação judicial do crime de tráfico de animais silvestres. In:

ENCONTRO NACIONAL DO CONPEDI, 18., 2009, Maringá. Anais [...]. Maringá: CONPEDI, 2009. p. 2448-2474. Disponível em: http://www.publicadireito.com.br/conpedi/manaus/arquivos/ anais/maringa/Maringa_integra.pdf. Acesso em: 27 nov. 2018.

QUEIROZ, Paulo. Funções do direito penal: legitimação versus deslegitimação do Sistema Penal. 3. ed. São Paulo: Editora Revista dos Tribunais, 2008.

RENCTAS - REDE NACIONAL DE COMBATE AO TRÁFICO DE ANIMAIS SILVESTRES. $1^{\circ}$ relatório nacional sobre o tráfico de fauna silvestre. 2001. Disponível em: http://www. renctas.org.br/trafico-de-animais/. Acesso: 17 dez. 2016.

SILVA, Paulo Afonso da. Direito ambiental constitucional. 9. ed. São Paulo: Editora 
Malheiros, 2011.

SINGER, Peter. Libertação animal. São Paulo: Editora WMF Martins Fontes, 2013.

TAKADA, Mariana; RUSCHEL, Caroline Vieira. A (in) eficácia das penas nos crimes ambientais. Revista Eletrônica de Iniciação Científica, Itajaí, v. 3, n. 3, 2012.

THOMÉ, Romeu. Manual de direito ambiental. 5. ed. Bahia: Editora Juspodivm, 2015.

VIVIANI, Rodrigo Andrade. $\mathrm{O}$ direito penal como instrumento destinado à proteção do meio ambiente: análise no contexto da constituição federal brasileira. Revista Eletrônica Direito e Política, Itajaí, v. 11, n. 2, 2016.

Como citar: VALADA, Daniela Cristina; SANTOS, José Eduardo Lourenço dos. A intervenção do direito penal no crime de tráfico de animais e a educação ambiental. Revista do Direito Público, Londrina, v. 14, n. 1, p. 103-120 , abr. 2019. DOI: 10.5433/1980-511X2019v14n1p103. ISSN: 1980-511X.

Recebido em: 08/05/2017.

Aprovado em: 26/02/2019. 